\title{
Do EMT students enrolled through a college course perform better in terms of course completion and exam success?
}

\author{
Daniel Armstrong, DPT, MS \& Kevin Rummel, MS, RN, NRP
}

POSTER PRESENTATION ABSTRACT | ORIGINAL RESEARCH CATEGORY

Introduction: This project was designed to determine the difference in student course completion rates and certifying exam scores in college vs. non-college formats. College students often have access to academic and student support resources which can include tutoring, libraries, computer labs, writing and math centers, counseling services, and services for students with disabilities. We hypothesized that EMT students enrolled through a college format are more likely to complete an EMT course and score higher on the state certifying exam.

Methods: A retrospective review of an EMT program that offered an EMT class both through a college as a credited course and as a non-credited course through continuing education was conducted. Both sets of students experienced the same course. Regardless of enrollment type the students were mixed into the same class. Five years of student data from 2013 to 2018 was examined retrospectively. A total of 350 student records were examined. Course completion rates were analyzed with descriptive statistics and compared with a z-test for two population proportions. State certifying exam scores were analyzed with descriptive statistics and compared with a two tailed independent sample t-test. The level of statistical significance $(\alpha)$ was set at 0.05 .

Results: Over the 5 years analyzed, 181 (51.71\%) students were enrolled through the college and 169 (48.29\%) students were enrolled in the continuing education department. There was no significant difference in course completion rates between the proportion of students enrolled through the college (54.67\%) and through continuing education $(62.13 \%)(P=0.16)$. The mean score on the state certifying exam was significantly lower for students enrolled through the college $(77.42, \mathrm{SD}=6.91)$ than for students enrolled through continuing education $(79.95, \mathrm{SD}=8.32)(P=0.02)$.

Discussion/Conclusions: Contrary to our hypothesis, students enrolled through the college scored lower on the state certifying exam and there was no statistical difference in course completion between the groups. Further research is needed to determine if course completion rates and exam scores differ between college-enrolled and non-college-enrolled students at other EMT programs. Further research is also needed to determine which resources improve student success so collegiate program directors can encourage students to utilize them.

Author Affiliations: Health, Physical Education, and Dance Department, Queensborough Community College, Queens, NY, USA.

Address for Correspondence: Daniel Armstrong, DPT, MS.

Email: darmstrong@qcc.cuny.edu

Conflicts of Interest/Funding Sources: By the JCEMS Submission Declaration

Form, all authors are required to disclose all potential conflicts of interest and funding sources. The authors declared that they have no conflicts of interest. The authors declared that they did not receive funding to conduct the program or research associated with this work.

Ethical Compliance: The authors attest that the research associated with this abstract was conducted in accordance with the JCEMS Ethics Guidelines.

Submission History: Received November 30, 2018; accepted for presentation and publication January 31, 2019.

Poster Presentation: This abstract was presented as a poster at the Academic Poster Session of the $26^{\text {th }}$ Annual Conference of the National Collegiate Emergency Medical Services Foundation; February 23, 2019; Pittsburgh, PA, USA.

Published Online: December 31, 2019

Published in Print: December 31, 2019 (Volume 2: Supplemental 1)

Reviewer Information: In accordance with JCEMS editorial policy, poster presentation abstracts undergo double-blind peer-review by at least two reviewers (JCEMS
Editorial Board members and/or independent reviewers) prior to acceptance fo r presentation and publication. JCEMS thanks the anonymous reviewers who contributed to the review of this work.

Copyright: ( 12019 Armstrong \& Rummel. This is an open access abstract distributed under the terms of the Creative Commons Attribution 4.0 International (CC BY 4.0) License, which permits unrestricted use, distribution, and reproduction in any medium, provided the original author and source are credited. The full license is available at: https://creativecommons.org/licenses/by/4.0/

Electronic Link: https://doi.org/10.30542/JCEMS.2019.02.S1.05 